Research article

\title{
The predictive role of serum and bronchoalveolar lavage cytokines and adhesion molecules for acute respiratory distress syndrome development and outcome
}

\author{
Panagiotis Agouridakis1, Despina Kyriakou2, Michael G Alexandrakis², Athanasios Prekates ${ }^{4}$, \\ Kostas Perisinakis ${ }^{5}$, Nikolaos Karkavitsas ${ }^{6}$ and Demosthenes Bouros ${ }^{3}$
}

\author{
${ }^{1}$ Intensive Care Unit, General Hospital of Rethymnon, Crete, Greece \\ 2Department of Hematology, University Hospital of Heraklion, Crete, Greece \\ 3Department of Pneumonology, University Hospital of Heraklion, Crete, Greece \\ ${ }^{4}$ Intensive Care Unit, Tzanion General Hospital of Pireus, Crete, Greece \\ ${ }^{5}$ Department of Medical Physics, University Hospital of Heraklion, Crete, Greece \\ ${ }^{6}$ Department of Nuclear Medicine, University Hospital of Heraklion, Crete, Greece
}

Correspondence: Demosthenes Bouros - bouros@med.uoc.gr

Received: 18 January 2002

Respir Res 2002, 3:25

Revisions requested: 26 February 2002

Revisions received: 16 May 2002

Accepted: 6 June 2002

Published: 23 October 2002

(C) 2002 Agouridakis et al; licensee BioMed Central Ltd. This is an Open Access article: verbatim copying and redistribution of this article are permitted in all media for any non-commercial purpose, provided this notice is preserved along with the article's original URL.

(Print ISSN 1465-9921; Online ISSN 1465-993X)

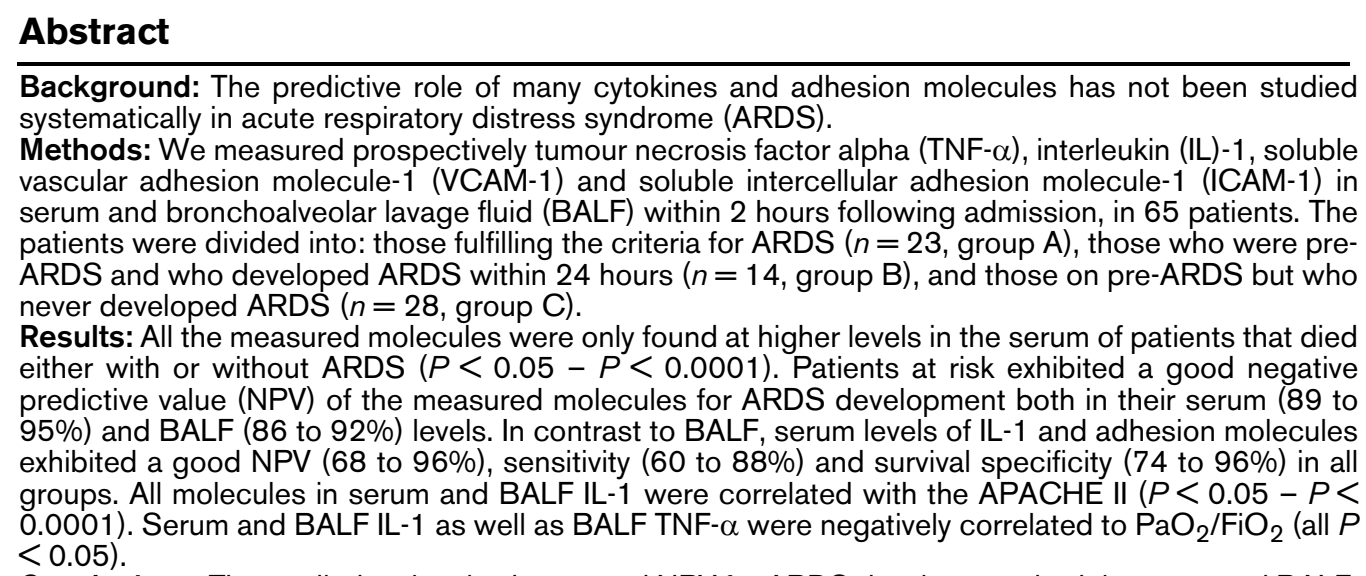

Conclusions: The studied molecules have good NPV for ARDS development both in serum and BALF. Serum rather than BALF levels seem to be related to outcome.

Keywords: ARDS, adhesion molecules, BAL, cytokines, survival

\section{Introduction}

Acute respiratory distress syndrome (ARDS) is characterised during the early phase by diffuse inflammation and increased microvascular permeability that cause diffused interstitial and alveolar oedema and persistent refractory hypoxemia [1]. A complex series of inflammatory events have been recognized during the development of ARDS 
but the exact sequence of the events remains unclear. Most of our understanding regarding pulmonary inflammation in ARDS is based on studies regarding bronchoalveolar lavage fluid (BALF) [2]. Various inflammatory mediators have been found to be increased in BALF in the early phase of ARDS, including endotoxin-binding proteins, tumour necrosis factor alpha (TNF- $\alpha$ ), interleukin (IL)-1, IL-6, chemokines, adhesive molecules as well as matrix metalloproteinases and their inhibitors [2-4].

Leukocyte activation and the free radical release, proteases, arachidonic acid metabolites, inflammatory and anti-inflammatory cytokines and TNF- $\alpha$ result in increased alveolar-capillary membrane permeability $[5,3]$. Cytokines are produced in the lung by local resident cells, such as alveolar macrophages, lung epithelial cells, and fibroblasts or by cells such as neutrophils, lymphocytes, and platelets arriving there as a response to local or systemic injury [2,47]. Elevated levels of proinflammatory cytokines, such as TNF- $\alpha$ and IL- 1 have been found in BALF and in plasma from ARDS patients [8]. Furthermore, IL- 8 is increased in BALF specimens from patients with ARDS as well as in patients at risk of developing ARDS [9]. According to various authors, TNF- $\alpha$ and IL-1 are probably produced very early in response to the original pathogenetic cause $[2,10]$. These early inflammatory reactions can induce the secretion of chemokines and other immunomodulators by endothelial cells, epithelial cells, and cells of the interstitium creating an intense local inflammatory response $[2,10]$. The subsequent events of these cellular/humoral interactions are important to the initiation and propagation of the inflammatory response leading to pulmonary injury [11].

The sequence of events in ARDS has been identified in animal models and in pulmonary microvascular endothelial cell culture. In response to IL-1b and TNF- $\alpha$, microvascular epithelium is activated and expresses intercellular adhesion molecule-1 (ICAM-1), vascular adhesion molecule-1 (VCAM-1) and selectins [12,13]. The adhesion molecules have been found to play an important role in cell interactions during inflammatory responses. ICAM- 1 is induced by lipopolysaccharide (LPS) and cytokines such as IL-1, TNF$\alpha$ [14-16], and subsequent interactions with lymphocyte function-associated antigen-1 (LFA-1) mediates a wide range of cellular responses. VCAM- 1 is also induced by cytokines, such as IL-1 and mediates the adhesion of mononuclear cells to the endothelium [15-17]. It has been found that cytokines, particularly IL-1 and TNF- $\alpha$, as well as endothelial cells, leukocytes and adhesion molecules appear to coordinate a cascade of interactions between leukocytes and endothelial cells, which result in tissue injury [18].

To our knowledge soluble adhesion molecules have not been studied in ARDS although their role in other inflamma- tory conditions is well known $[19,20]$. In the effort to investigate the sequence and severity of the events during the development of ARDS and to correlate this with clinical outcome, we measured soluble adhesion molecules of serum and BALF in a series of 65 patients with ARDS or preARDS.

\section{Material and methods Patients}

We studied prospectively 65 patients who were admitted into the intensive care unit (ICU) with severe respiratory failure. Forty patients were male with mean (SD) age $44 \pm 21$ years (range, 21-77, median 55) and 25 were female with mean (SD) age $47 \pm 18$ years (range, 18-78, median 56). The patients were classified into 4 groups: The first group (group A) included 23 patients (14 male, 9 female; median age 53, range 18-78 years) fulfilling the criteria of ARDS [1]. All these patients were supported mechanically for their respiratory failure $\left(\mathrm{PaO}_{2} / \mathrm{FiO}_{2} 127 \pm 11\right.$, APACHE II 19.6 \pm 1.1 ). The cause of ARDS was trauma (9), pneumonia (3), sepsis (5), transfusions (2), pancreatitis (2), intoxication (1), and burns (1).

The second group (group B) included 14 patients (8 male, 6 female; median age 56; range 19-77 years) on mechanical respiratory support who had at least one condition from those suggested by Fowler et a/[21] as risk factors for ARDS development. All patients $\left(\mathrm{PaO}_{2} / \mathrm{FiO}_{2} 235 \pm 23\right.$, APACHE II $20.9 \pm 1.3$ ) in this group developed ARDS within 48 hours. The cause of ARDS was sepsis (3), pneumonia (4), trauma (6), and pancreatitis (1).

The third group (group C) included 28 patients at high risk for ARDS development who did not develop ARDS (18 male, 10 female; median age 51 ; range $19-73$ years; $\mathrm{PaO}_{2} / \mathrm{FiO}_{2} 277 \pm 21$; APACHE II $17.1 \pm 1.9$ ). The cause of disease was trauma (15), sepsis (5), pneumonia (2), transfusions (2), intoxication (2), arrest (1), and pancreatitis (1).

The control group (group D) included 40 healthy individuals who had minimal surgery (e.g. lymph node biopsy, nasal diaphragm correction, tonsillectomy, etc.) and received anesthesia for a short period of time. Twenty-six were male, median age 35 years (range 19-70) and 14 were female, median age 38 years (range $25-73$ ).

For patients' classification, the following criteria were employed:

1. the ARDS criteria of the American-European Consensus Conference on ARDS [1]: (a) acute onset; (b) bilateral chest radiographic infiltrates; (c) pulmonary artery occlusion pressure of $\leq 18 \mathrm{mmHg}$, or no evidence of left atrial hypertension, and (d) impaired oxygenation regardless of the 
positive end-expiratory pressure (PEEP) concentration, with a $\mathrm{PaO}_{2} / \mathrm{FiO}_{2}$ ratio of $\leq 300$ torr for acute lung injury (ALI) and $\leq 200$ torr for ARDS;

2. the high risk criteria for ARDS development according to Fowler et al [21];

3. the criteria for pneumonia according to the EPIC study [22], and

4. the criteria for septic syndrome according to Bone et al [23].

The Acute Physiology And Chronic Health Evaluation-II (APACHE II) scoring system was used for grading disease severity [24].

The protocol was approved by the Ethics Committee of our institution.

\section{Methods}

After admission to the ICU, blood samples were obtained from a central venous line within 2 hours. APACHE II score and $\mathrm{PaO}_{2} / \mathrm{FiO}_{2}$ values were obtained at the time of sample collection. The samples were obtained through a SwanGanz catheter.

The blood was collected in a heparinized vacutainer tube and kept immediately at $4^{\circ} \mathrm{C}$. After centrifugation at 1500 g at $4^{\circ} \mathrm{C}$, the plasma was kept at $-80^{\circ} \mathrm{C}$ until measurement. At the same time BALF was obtained by fiberoptic bronchoscopy. The fluid was filtered through nylon net to remove the mucous secretions, and centrifuged at $500 \mathrm{~g}$ for 10 min to remove cells. The supernatant was kept in cryotubes at $-80^{\circ} \mathrm{C}$ in aliquots of $0.5 \mathrm{ml}$. The method of microlavage was used as described previously [25]. The following criteria were used for an acceptable sample:

(a) the procedure should be shorter than $1 \mathrm{~min}$, while the time of saline staying in the lungs should be less than $20 \mathrm{~s}$;

(b) recovery of more than $50 \%$ of the saline used for the lavage;

(c) absence of obvious blood contamination in the BALF, and

(d) the level of urea in the BALF should be more than 0.4 $\mathrm{mmol}$. The urea level was used as an index of BALF dilution $[25,26]$.

\section{Measurement of the plasma cytokines and soluble adhe- sion molecules}

The assay method for cytokine measurement was the same for blood and BALF samples. Determination of plasma cy- tokines and adhesion molecules was done with the solid phase enzyme-linked immunosorbent assay (ELISA) methodology based on the quantitative immunometric sandwich enzyme immunoassay technique $[27,28]$. Reagents for the various cytokines were obtained from several sources (kits of R\&D for TNF- $\alpha$, kits of Genzyme for sICAM-1, and sVCAM-1, and RIA kits for IL-1) and were used according to manufacturer's instructions. All the measurements were done within 6 months of the sample collection. Intra-assay and interassay reproducibility was checked and found to be more than $90 \%$. To calculate the dilution factor of the BALF, urea values in the plasma and BALF were used because this low molecular weight substance is found in body fluids at the same concentration as in blood [29].

\section{Statistical analysis}

Data analysis was carried out using SPSS 8.0 statistical software (SPSS Inc., Chicago, IL). Results are expressed as mean $\pm 1 \mathrm{SD}$, or median (range), unless otherwise indicated. The Mann-Whitney non-parametric test was used to compare the mean values of cytokines in blood and BALF in the various groups. Receiver Operative Characteristic (ROC) analysis was used to identify predictive values for surviving patients $[30,31]$. To compare the values of the same cytokine in the various study groups, the KruskalWallis test was used. The Spearman's rank order correlation coefficient was used to determine correlation between the cytokines and the various other parameters measured. A $P$ value $<0.05$ was considered to be statistically significant.

\section{Results}

The mean time of staying in the ICU did not differ among the three groups. Twelve ARDS patients (52\%) died within 15 days after submission to the ICU, while $32 \%$ of groups $\mathrm{B}$ and $\mathrm{C}$ (14 patients) died mainly due to respiratory failure.

Predictive capabilities of mediators for the onset of ARDS The median values and the range of the measured cytokines in BALF and serum in the three patient groups are shown in Table 1. BALF TNF- $\alpha$ levels were higher in patients with ARDS (group A) than in patients at risk for ARDS (group B) and those who never developed ARDS (group C) ( $P<0.0001$ for both). On the contrary, the other cytokines and adhesive molecules measured in BALF were not significantly different among the study groups $(P>$ 0.05). Serum levels of sVCAM were higher in those who never developed ARDS (group C), while levels of the other cytokines and adhesive molecules were not significantly different.

Predictive serum and BALF levels of all studied molecules for ARDS development in patients at risk (groups $B$ and C) are shown in Table 2. The two groups of molecules studied (proinflammatory cytokines and adhesion molecules) 

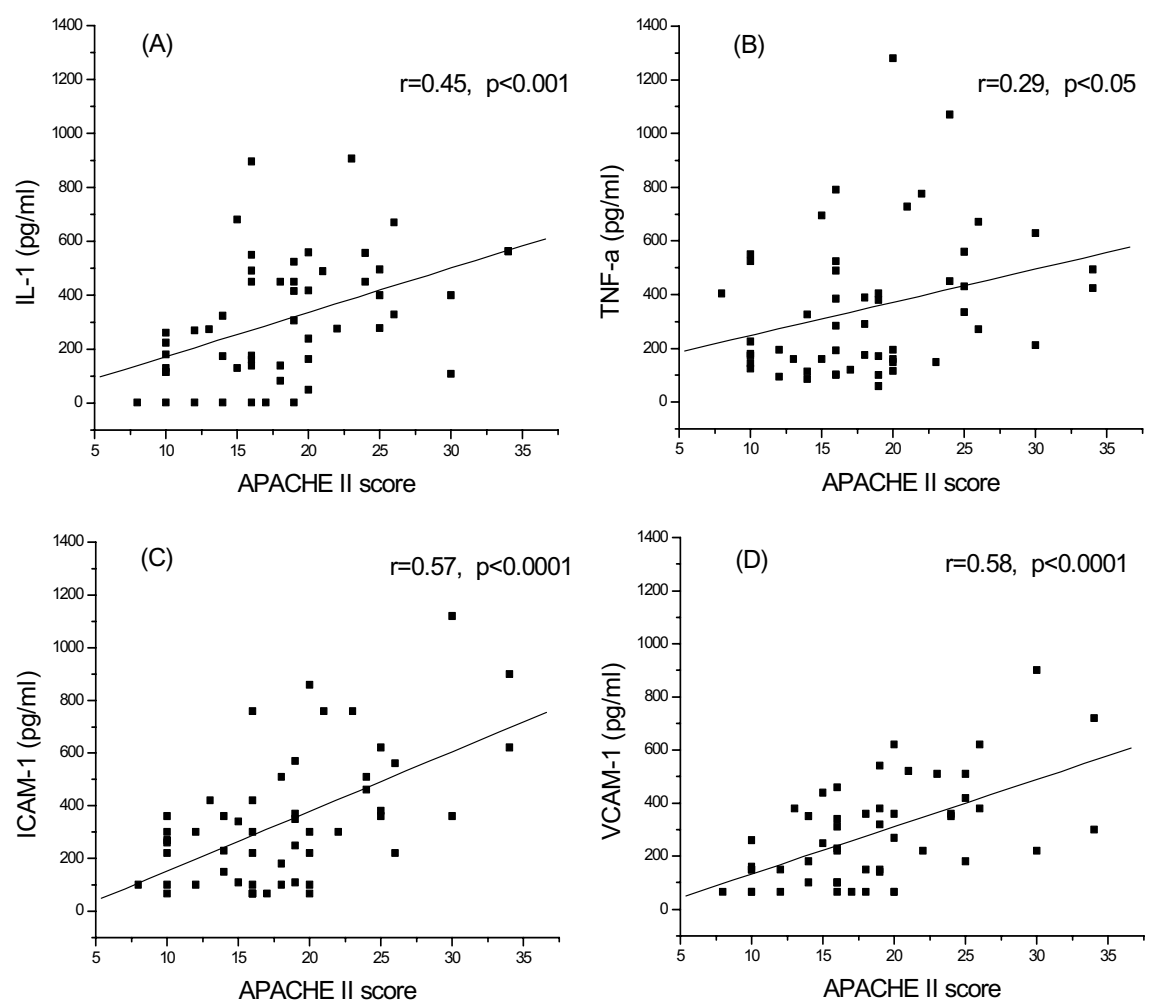

Serum levels of IL-1 (A), TNF- $\alpha$ (B), ICAM-1 (C) and VCAM-1 (D) are significantly correlated to the APACHE II score. IL-1 = interleukin-1; TNF- $\alpha=$ tumour necrosis factor-alpha; ICAM-1 = intercellular adhesion molecule-1; VCAM = vascular adhesion molecule

showed good negative predictive values for ARDS development both in serum ( 89 to $95 \%$ ) and BALF (86 to $92 \%$ ). In a multivariate analysis model adjusting for age and severity, none of the studied mediators were found to be an independent factor for ARDS development.

\section{Predictive capabilities of mediators for survival}

The median values and the range in BALF and serum of the studied mediators in survivors and non-survivors in all categories are shown in Table 3. All studied mediators were found at higher levels in the serum of non-survivors (IL-1, $P$ $<0.0001$; TNF- $\alpha, P<0.05$; sICAM-1, $P<0.0001$; sVCAM-1, $P<0.0001$, respectively).

ARDS patients (group A) who did not survive had higher serum adhesion molecule levels than survivors (Table 4). Patients at risk who developed ARDS (group B) or who did not develop ARDS (group $\mathrm{C}$ ) and did not survive had high- er levels of all measured molecules in their serum $(P<0.01$ to $P<0.0001$ ) (Table 5). Predictive serum and BALF levels of all studied molecules for surviving are shown in Tables 6 and 7. In contrast to BALF values, serum levels of IL-1 and adhesion molecules exhibited a high positive predictive value, sensitivity and specificity for surviving in all groups. In a multivariate analysis model adjusting for age and severity we found that serum IL-1 $(P=0,002)$ and serum ICAM-1 $(P=0,009)$ were independent factors for death.

\section{Correlations of the studied cytokines}

Serum levels of all measured cytokines and adhesion molecules were significantly correlated to APACHE II score (Fig. 1). BALF levels of IL-1 and TNF- $\alpha$ were significantly negatively correlated to $\mathrm{PaO}_{2} / \mathrm{FiO}_{2}$ values (Fig. $2 \mathrm{~A}$ and $2 \mathrm{~B}$, respectively). BALF levels of ICAM-1 (Fig. 2C) were significantly positively correlated to APACHE II scores. Serum 
levels of VCAM-1 were negatively correlated to $\mathrm{PaO}_{2} / \mathrm{FiO}_{2}$

(Fig. 2D).

\section{Figure 2}
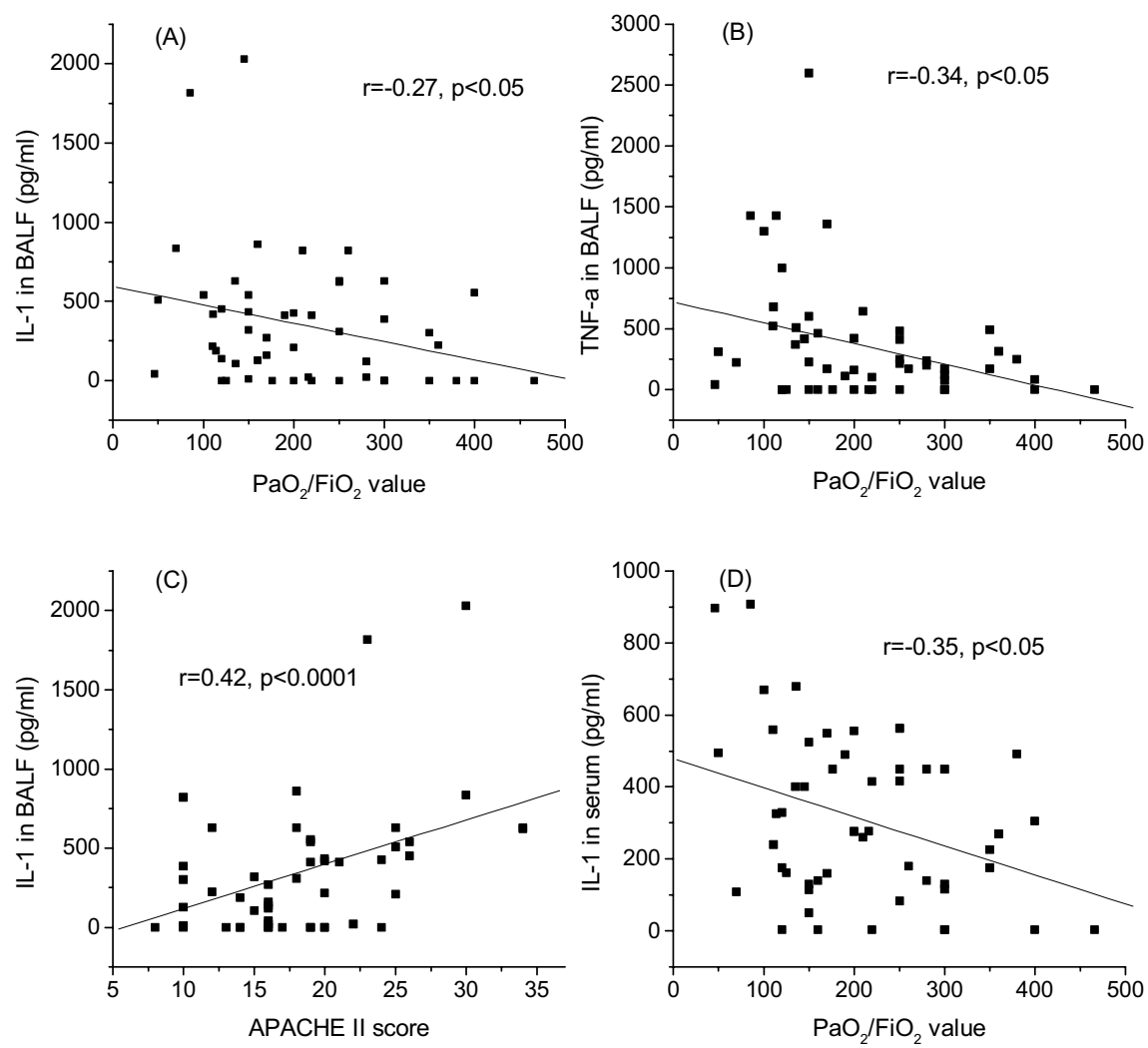

Bronchoalveolar lavage fluid (BALF) levels of IL-1 (A) and TNF- $\alpha$ (B) are significantly negatively correlated to the PaO $/ \mathrm{FiO}_{2}$ value. BALF levels of IL1 (C) are significantly positively correlated to the APACHE II score. Serum levels of IL-1 are negatively correlated to $\mathrm{PaO}_{2} / \mathrm{FiO}_{2}(\mathrm{D})$. IL-1 $=$ interleukin-1; TNF- $\alpha=$ tumour necrosis factor-alpha

\section{Table 1}

Median (range) bronchoalveolar lavage fluid (BALF) and serum levels (pg/ml) of cytokines and adhesion molecules measured in the three groups of patients and controls

\begin{tabular}{|c|c|c|c|c|c|c|}
\hline & \multicolumn{2}{|c|}{ Group $1(n=23)$} & \multicolumn{2}{|c|}{ Group $2(n=14)$} & \multicolumn{2}{|c|}{ Group $3(n=28)$} \\
\hline & BALF & Serum & BALF & Serum & BALF & Serum \\
\hline IL-1 & $267(0-2030)$ & 364 (3-908) & $339(0-630)$ & $408(160-556)$ & $179(0-860)$ & $178(3-563)$ \\
\hline TNF- $\alpha$ & $463(0-2600)$ & $204(60-790)$ & $210^{\star \star}(0-680)$ & $383(160-490)$ & $145^{\star \star}(0-643)$ & $254(93-1280)$ \\
\hline SICAM-1 & $970(540-2460)$ & $320(66-1120)$ & $1440(460-2220)$ & $365(220-620)$ & $1710(260-4620)$ & $255(66-900)$ \\
\hline sVCAM & $350(156-528)$ & $355^{\star}(66-900)$ & $416(92-536)$ & $330^{*}(180-510)$ & $330(52-924)$ & $150(66-720)$ \\
\hline
\end{tabular}

${ }^{\star} P<0.05$ versus group $3 ;{ }^{\star \star} P<0.0001$ versus group 1 . Comparisons were done using the Kruskal-Wallis test. IL-1 $=$ interleukin- $1 ;$ TNF- $\alpha=$ tumour necrosis factor-alpha; sICAM-1 = serumintercellular adhesion molecule-1; sVCAM = serum vascular adhesion molecule 
Predictive (\%) serum and bronchoalveolar lavage fluid (BALF) levels (pg/ml) of the measured cytokines and adhesion molecules for acute respiratory distress syndrome development in patients at risk $(n=42)$

\begin{tabular}{|c|c|c|c|c|c|c|}
\hline & Criterion & PPV & NPV & Sensitivity & Specificity & $95 \% \mathrm{Cl}$ \\
\hline & \multicolumn{6}{|c|}{ Serum } \\
\hline IL-1 & 225 & 39 & 94 & 88 & 58 & $0.55-0.87$ \\
\hline TNF- $\alpha$ & 325 & 38 & 89 & 75 & 62 & $0.39-0.74$ \\
\hline sICAM-1 & 300 & 42 & 90 & 75 & 69 & $0.48-0.81$ \\
\hline \multirow[t]{2}{*}{ sVCAM } & $>260$ & 50 & 95 & 88 & 73 & $0.59-0.89$ \\
\hline & \multicolumn{6}{|c|}{ BALF } \\
\hline IL-1 & 136 & 32 & 87 & 75 & 50 & $0.35-0.70$ \\
\hline TNF- $\alpha$ & 82 & 32 & 92 & 88 & 42 & $0.44-0.77$ \\
\hline sICAM-1 & 1540 & 35 & 88 & 75 & 58 & $0.38-0.73$ \\
\hline sVCAM & 392 & 42 & 86 & 63 & 73 & $0.45-0.79$ \\
\hline
\end{tabular}

$\mathrm{PPV}=$ positive predictive value; NPV = negative predictive value; $\mathrm{Cl}=$ confidence interval; IL-1 = interleukin-1; TNF- $\alpha=$ tumour necrosis factoralpha; sICAM-1 = serumintercellular adhesion molecule-1; sVCAM = serum vascular adhesion molecule

Table 3

Median (range) bronchoalveolar lavage fluid (BALF) and serum levels (pg/ml) of the measured cytokines and adhesion molecules in all patients (groups $A+B+C$ ) whether or not they survived

\begin{tabular}{lcccc}
\hline \multicolumn{2}{c}{ BALF } & Serum \\
\cline { 2 - 5 } & Survivors $(n=38)$ & Non-survivors $(n=27)$ & Survivors $(n=38)$ & Non-survivors $(n=27)$ \\
\cline { 2 - 5 } IL-1 & $215(0-860)$ & $410(0-2030)$ & $140(3-558)$ & $450^{* *}(3-908)$ \\
TNF- $\alpha$ & $170(0-2600)$ & $222(0-1428)$ & $194(94-790)$ & $405^{*}(60-1280)$ \\
sICAM-1 & $1140(260-4620)$ & $1520(680-3780)$ & $180(66-360)$ & $460^{* *}(66-1120)$ \\
sVCAM & $312(136-792)$ & $356(52-924)$ & $150(66-310)$ & $380^{* *}(140-900)$
\end{tabular}

${ }^{*} P<0.05,{ }^{* *} P<0.0001$ versus survivors group. Comparisons were done using the Mann-Whitney test. IL-1 $=$ interleukin- $1 ;$ TNF- $\alpha=$ tumour necrosis factor-alpha; sICAM-1 = serumintercellular adhesion molecule-1; sVCAM = serum vascular adhesion molecule

\section{Discussion}

We investigated two categories of soluble molecules that might be involved in the pathogenesis of ARDS: proinflammatory cytokines and adhesion molecules. We studied these molecules within the first 2 hours of admission, in order to establish factors that could have prognostic value for the development, severity, course and outcome of patients with ARDS and at risk of ARDS.

The interesting finding of this study was that all the measured molecules were found at significantly higher levels only in the serum of patients that died either with or without ARDS $(P<0.05$ to $P<0.0001)$ (Table 3$)$. We also found that the proinflammatory cytokine TNF- $\alpha$ was elevated in the BALF of ARDS patients compared to at risk patients, confirming previous observations [30,31]. The most likely explanation is that the increased TNF- $\alpha$ and IL-1 levels found in the BALF of our patients were produced by acti- vated pulmonary macrophages or other cells. These cells are located in lung interstitium, alveolar space and capillaries in humans [2,32-35]. It is known that endothelial cell activation and VCAM-1 expression is induced mainly by IL$1 \mathrm{~b}$ and TNF- $\alpha$. However, the levels of TNF- $\alpha$ and IL-1 were not predictive for the development of the syndrome.

BALF soluble adhesion molecules sICAM and sVCAM did not differ among the three groups of patients. This means that lung endothelial cell inflammation existed in all the critically ill patients studied. It seems that endothelial damage alone is not enough for cell extravasation in the interstitium but the presence of a continuous chemotactic gradient is also essential; this gradient is produced by IL-6, IL-8 and possibly other C-X-C chemokines that are secreted by resident cells upon activation or arrive there through the circulation $[6,7,32]$. 
Median (range) bronchoalveolar lavage fluid (BALF) and serum levels (pg/ml) of the measured cytokines and adhesion molecules in acute respiratory distress syndrome patients (group A) whether or not they survived

\begin{tabular}{|c|c|c|c|c|}
\hline & \multicolumn{2}{|c|}{ BALF } & \multicolumn{2}{|c|}{ Serum } \\
\hline & Survivors $(n=11)$ & Non-survivors $(n=12)$ & Survivors $(n=11)$ & Non-survivors $(n=12)$ \\
\hline $\mathrm{IL}-1$ & $215(10-435)$ & $450(0-2030)$ & $130(50-558)$ & $400(3-908)$ \\
\hline TNF- $\alpha$ & $600(0-2600)$ & $310(0-1428)$ & $362(116-790)$ & $212(60-695)$ \\
\hline sICAM-1 & $960(540-2460)$ & $980(680-2140)$ & $160(66-300)$ & $360^{*}(66-1120)$ \\
\hline sVCAM & $312(156-392)$ & $356(236-528)$ & $100(66-250)$ & $380^{\star *}(140-900)$ \\
\hline
\end{tabular}

${ }^{*} P<0.05,{ }^{* *} P<0.01$, versus survivors group. Comparisons were done using the Mann-Whitney test. IL-1 = interleukin- $1 ;$ TNF- $\alpha=$ tumour necrosis factor-alpha; sICAM-1 = serumintercellular adhesion molecule-1; sVCAM = serum vascular adhesion molecule

\section{Table 5}

Median (range) bronchoalveolar lavage fluid (BALF) and serum levels (pg/ml) of the measured cytokines and adhesion molecules in at risk patients who developed or did not develop acute respiratory distress syndrome (groups B $+\mathrm{C}$ )

\begin{tabular}{|c|c|c|c|c|}
\hline & \multicolumn{2}{|c|}{ BALF } & \multicolumn{2}{|c|}{ Serum } \\
\hline & Survivors $(n=27)$ & Non-survivors $(n=15)$ & Survivors $(n=27)$ & Non-survivors $(n=15)$ \\
\hline IL-1 & $216(0-860)$ & $410(0-630)$ & $150(3-306)$ & $450^{\star \star}(400-563)$ \\
\hline TNF- $\alpha$ & $170(0-680)$ & $180(0-481)$ & $187(94-775)$ & $440^{*}(170-1280)$ \\
\hline sICAM-1 & $1250(260-4620)$ & $1860(760-3780)$ & $220(66-360)$ & $565^{\star *}(350-900)$ \\
\hline sVCAM & $312(136-792)$ & $356(52-924)$ & $150(66-310)$ & $370^{\star \star}(300-720)$ \\
\hline
\end{tabular}

${ }^{\star} P<0.01,{ }^{\star *} P<0.0001$, versus survivors group. Comparisons were done using the Mann-Whitney test. IL-1 = interleukin- $;$; TNF- $\alpha=$ tumour necrosis factor-alpha; sICAM-1 = serumintercellular adhesion molecule-1; sVCAM = serum vascular adhesion molecule

The severity of lung injury seems to be related negatively with BALF IL-1, TNF- $\alpha$ and $\mathrm{PaO}_{2} / \mathrm{FiO}_{2}$ (Fig. 1C). The same was true for serum IL-1 and $\mathrm{PaO}_{2} / \mathrm{FiO}_{2}$ (Fig. 1D). All the studied molecules in the serum were positively correlated with the APACHE II score (Fig. 1B) as was BALF IL-1 (Fig. $1 \mathrm{~A})$. It is probable that these cytokines are closely related to the extension of tissue damage and organ failure. In our patients, TNF- $\alpha$ was correlated with sVCAM and sICAM confirming a causal relationship to the extent of endothelium activation. As there was no difference in the BALF levels of these soluble adhesion molecules among the three groups, it seems that endothelial activation alone is not related to ARDS development, but correlates with the extension of tissue damage since they also correlated with the APACHE II score.

Patients with ARDS (group A) who died had elevated serum levels of sICAM and sVCAM (Table 5) and these could be used as a survival predictor factor. Some investigators have reported that persistent elevation of inflammatory cytokines may be predictive of ARDS development in at risk patients [14]. It is known that enhanced or prolonged response with early phase inflammatory cytokines could produce tissue damage, while early response with early phase cytokines could lead to inefficient elimination of pathogens and to poor outcome $[13,14,33]$. Patients at risk who did not develop ARDS had lower serum levels of sVCAM compared to those at risk who developed ARDS (Table 1). Since we did not examine our patients serially, we do not know if there is a critical value over time that could predict the course of the disease in these patients. However, the most interesting finding of this study is that the serum levels of the measured cytokines and adhesion molecules can predict survival. Indeed, and in contrast to BALF values, serum levels of IL-1 and adhesion molecules exhibited a high positive predictive value, sensitivity and specificity for survival in all groups.

\section{Conclusion}

In conclusion, our data show that the two groups of molecules (proinflammatory cytokines and adhesion molecules) studied in a single measurement, within 2 hours of hospital 
Predictive (\%) serum levels $(\mathrm{pg} / \mathrm{ml})$ for surviving patients of all groups $(n=65)$

\begin{tabular}{lcccccc}
\hline & Criterion & PPV & NPV & Sensitivity & Specificity & 95\% Cl \\
\cline { 2 - 7 } & & & & & 93 & $0.75-0.95$ \\
IL-1 & 306 & 91 & 86 & 84 & 74 & $0.51-0.78$ \\
TNF- $\alpha$ & 334 & 68 & 68 & 60 & 93 & $0.80-0.97$ \\
sICAM-1 & 300 & 91 & 86 & 84 & 96 & $0.87-0.99$ \\
sVCAM-1 & 270 & 96 & 90 & 88 &
\end{tabular}

$\mathrm{PPV}=$ positive predictive value; NPV $=$ negative predictive value; $\mathrm{Cl}=$ confidence interval; $\mathrm{IL}-1=$ interleukin- 1 ; TNF- $\alpha=$ tumour necrosis factoralpha; sICAM-1 = serumintercellular adhesion molecule-1; sVCAM = serum vascular adhesion molecule

Table 7

Predictive (\%) bronchoalveolar lavage fluid levels $(\mathrm{pg} / \mathrm{ml})$ of the measured cytokines and adhesion molecules for surviving in patients of all groups $(n=65)$

\begin{tabular}{|c|c|c|c|c|c|c|}
\hline & Criterion & PPV & NPV & Sensitivity & Specificity & $95 \% \mathrm{Cl}$ \\
\hline $\mathrm{IL}-1$ & 385 & 67 & 65 & 56 & 74 & $0.42-0,70$ \\
\hline TNF- $\alpha$ & 172 & 56 & 60 & 60 & 56 & $0.37-0.66$ \\
\hline sICAM-1 & 660 & 58 & 100 & 100 & 33 & $0.47-0.75$ \\
\hline sVCAM-1 & 312 & 60 & 68 & 72 & 56 & $0.48-0.75$ \\
\hline
\end{tabular}

PPV $=$ positive predictive value; NPV = negative predictive value; $\mathrm{Cl}=$ confidence interval; IL-1 $=$ interleukin- 1 ; TNF- $\alpha=$ tumour necrosis factoralpha; sICAM-1 = serumintercellular adhesion molecule-1; sVCAM = serum vascular adhesion molecule

admission, are found at higher levels only in the serum of patients that died either with or without ARDS, providing a good negative predictive value for ARDS development both in serum and BALF. Further studies with serial BALF and serum measurements should be designed to investigate the complex network of these molecules and their inhibitors in ARDS or at risk for ARDS and their value as predictive factors.

\section{Abbreviations}

$A L I=$ acute lung injury; ARDS = acute respiratory distress syndrome; $\mathrm{BALF}=$ bronchoalveolar lavage fluid; ICAM-1 = intercellular adhesion molecule-1; ICU = intensive care unit; IL-1 = interleukin- 1 ; LFA-1 = lymphocyte function-associated antigen-1; LPS = lipopolysaccharide; NPV $=$ negative predicted value; $\mathrm{PEEP}=$ positive end-expiratory pressure; $\mathrm{PPV}=$ positive predictive value; $\mathrm{ROC}=$ Receiver Operative Characteristic; TNF- $\alpha=$ tumour necrosis factor-alpha; VCAM-1 = vascular adhesion molecule-1.

\section{References}

1. Bernard G, Artigas A, Brigham K, Carlet J, Falke K, Judson L, Lamy M, Legal J, Morris A, Sprucg R: The American-European Consensus Conference on ARDS Definitions, Mechanisms, Relevant Outcomes, and Clinical Trial Coordination. $A m J$ Respir Crit Care Med 1994, 149:818-824

2. Pugin J, Ricou B, Steinberg KP, Suter RM, Martin TR: Proinflammatory activity in bronchoalveolar lavage fluid from patients with ARDS, a prominent role for interleukin 1. Am J Respir Crit Care Med 1996, 153:1850-1856

3. Rinaldo JE, Christman JW: Mechanisms and mediators of the adult respiratory distress syndrome. Clin Chest Med 1990, 11:621-629
4. Torii K, lida K, Miyazaki Y, Saga S, Kondoh Y, Taniguchi H, Taki F, Takagi K, Matsuyama M, Suzuki R: Higher concentrations of matrix metalloproteinases in bronchoalveolar lavage fluid of patients with adult respiratory distress syndrome. $A m J$ Respir Crit Care Med 1997, 155:43-46

5. Meduri GU, Kanangat S, Stefan J, Tolley E, Schaberg D: Cytokines IL-1beta, IL-6, and TNF-alpha enhance in vitro growth of bacteria. Am J Respir Crit Care Med 1999, 160:961-967

6. Hierholzer C, Kalff JC, Omert L, Tsukada K, Loeffert JE, Watkins SC, Billiar TR, Tweardy DJ: IL-6 production in hemorrhagic shock is accompanied by neutrophil recruitment and lung injury. Am J Physiol 1998, 275:L611-L621

7. Johnson JL, Moore EE, Tamura DY, Zallen G, BiffI WL, Silliman CC: IL-6 augments neutrophil cytotoxic potential via selective enhancement of elastase release. J Surg Res 1998, 76:91-94

8. Suter PM, Suter S, Girardin E, Roux-Lombard P, Grau GE, Dayer J-M: High bronchoalveolar levels of tumor necrosis factor and its inhibitors, interleukin-1, interferon, and elastase in patients with adult respiratory distress syndrome after trauma, shock or sepsis. Am Rev Respir Dis 1992, 145:1016-1022

9. Donnelly SC, Strieter RM, Kundel SL, Walz A, Robertson CR, Carter DC, Grant IS, Pollok AJ, Haslett C: Interleukin-8 and development of adult respiratory distress syndrome in at-risk patient groups. Lancet 1993, 341:643-647

10. Standiford TJ, Kunkel SL, Basha MA, Chensue SW, Lynch JP, Toews GB, Westwick J, Strieter RM: Interleukin-8 gene expression by pulmonary epithelial cell line. A model for cytokine networks in the lung. J Clin Invest 1990, 86:1945-1953

11. Strieter RM, Kunkel SL: Acute lung injury: the role of cytokines in the elicitation of neutrophils. J Investig Med 1994, 42:640651

12. Meduri GU, Chinn A, Leeper K, Wunderink RG, Tolley E, WinerMuram HT, Khare V, Eltorky M: Corticosteroid rescue treatment of progressive fibroproliferation in late ARDS: patterns of response and predictors of outcome. Chest 1994, 105:15161527 
13. Pugin J, Verghese G, Widmer MC, Matthay MA: The alveolar space is the site of intense inflammatory and profiberotic reaction in the early phase of acute respiratory distress syndrome. Crit Care Med 1999, 27:304-312

14. Meduri GU, Headley S, Kohler G, Stentz F, Tolley E, Umberger R, Leeper K: Persistent elevation of inflammatory cytokines predicts a poor outcome over time. Chest 1995, 107:1062-1073

15. Moss M, Gillespi MK, Ackerson L, Moore FA, Moore EE, Parson PE: Endothelial cell activity varies in patients at risk for the adult respiratory distress syndrome. Crit Care Med 1996, 24:1782-1786

16. Armstrong L, Thickett DR, Christie SJ, Kendall H, Millar AB: Increased expression of functionally active membrane-associated tumor necrosis factor in acute respiratory distress syndrome. Am J Respir Cell Mol Biol 2000, 22:68-74

17. Sterner-Kock A, Braun RK, Schrenzel MD, Hyde DM: Recombinant tumor necrosis factor-alpha and platelet-activating factor synergistically increase intercellular adhesion molecule- 1 and E-selectin-dependent neutrophil adherence to endothelium in vitro. Immunology 1996, 87:454-460

18. Shanley TP, Warner RL, Ward PA: The role of cytokines and adhesion molecules in the development of inflammatory injury. Mol Med Today 1995, 1:40-45

19. Zissel G, Baumer I, Schlaak M, Muller-Quernheim J: In vitro release of interleukin-15 bronchoalveolar lavage cells and peripheral blood mononuclear cells from patients with different lung diseases. Eur Cytokine Netw 2000, 11:105-112

20. Cassatella MA, McDonald PP: Interleukin-15 and its impact on neutrophil function. Curr Opin Hematol 2000, 7:174-177

21. Fowler AA, Hamman RF, Good JT, Benson K, Baird M, Eberle DJ Petty TL: Adult respiratory distress syndrome: risk with common predispositions. Ann Intern Med 1983, 98:593-597

22. Vincent JL, Bihari DJ, Suter PM, Bruing HA, White J, Nicolas-Chanoin $\mathrm{MH}$, Wolff M, Spencer RC, Hemmer M: Prevalence of nosocomial infection in Intensive Care Units in Europe. Results of the European Prevalence of Infection in Intensive Care (EPIC) study. EPIC International Advisory Committee. JAMA 1995, 274:639-644

23. Bone R, Balk RA, Cerra FB, Dellinger RP, Fein AM, Knous WA, Schein RM, Sibbald WJ: The ACCP/SCCM Consensus Conference Committee: American College of Chest Physicians/Society of Critical Care Medicine Consensus Conference: Definitions for sepsis and organ failure and guidelines for the use of innovative therapies in sepsis. Crit Care Med 1992, 20:864-874

24. Knaus WA, Draper EA, Wagner DP, Zimmerman JE: APACHE II: a severity of disease classification system. Crit Care Med 1985, 13:818-829

25. Baldwin DR, Wise R, Andrews JM, Honeybourne D: Microlavage: a technique for determining the volume of epithelial lining fluid. Thorax 1991, 46:658-662

26. Walters $\mathrm{EH}$, Gardiner PV: Bronchoalveolar lavage as a research tool. Thorax 1991, 46:613-618

27. Kyriakou DS, Alexandrakis MG, Tzardi M, Stephanaki K, Eliopoulos GD: Downregulation of CD43 in RAEB and RAEB-T patients. Am J Hematol 2000, 63:20-27

28. Grassi G, Frobert Y, Pradelles PH, Chercuitte F, Gruaz D, Dayer JM, Poubelle PE: Production of monoclonal antibodies against IL-1a and IL-1b: development of the two-enzyme immunometric assays (EIA) using acetylcholinesterase and their application to biological media. $J$ Immunol Meth 1989, 123:193-210

29. Kyriakou DS, Papadaki HA, Eliopoulos AG, Foundoulakis A, Alexandrakis MG, Eliopoulos GD: Serum soluble IL-6 receptor concentrations correlate with stages of multiple myeloma defined by serum beta 2 -microglobulin and $\mathrm{C}$-reactive protein. Int $\mathrm{J} \mathrm{He}$ matol 1997, 66:367-371

30. Zweig $\mathrm{MH}$, Campbell G: Receiver operating characteristic (ROC) plots: a fundamental evaluation tool in clinical medicine. Clin Chem 1993, 39:561-577

31. Heffner JE, Brown LK, Barbieri CA: Diagnostic value of tests that discriminate between exudative and transudative pleural effusions. Chest 1997, 111:970-980

32. Hyers TM, Tricomi SM, Detterimeier PA, Fowler AA: Tumor necrosis factor levels in serum and bronchoalveolar lavage fluid of patients with the adult respiratory distress syndrome. Am Rev Respir Dis 1991, 144:268-271
33. Suter RM, Suter S, Girardin E, Roux-Lombard P, Grau GE, Dayer $\mathrm{J}-\mathrm{M}$ : High bronchoalveolar levels of tumor necrosis factor and its inhibitors interleukin-1, interferon, and elastase in patients with adult respiratory distress syndrome after trauma, shock or sepsis. Am Rev Respir Dis 1992, 145:1016-1022

34. Kiehl MG, Ostermann H, Thomas M, Muller C, Cassens U, Kienast $\mathrm{J}$ : Inflammatory mediators in bronchoalveolar lavage fluid and plasma in leukocytopenic patients with septic shock-induced acute respiratory distress syndrome. Crit Care Med 1998, 26:1194-1199

35. Meduri GU, Kohler G, Headley S, Tolley E, Stentz F, Postlethwaite A: Inflammatory cytokines in the BAL of patients with ARDS. Persistent elevation over time predicts poor outcome. Chest 1995, 108:1303-1314 